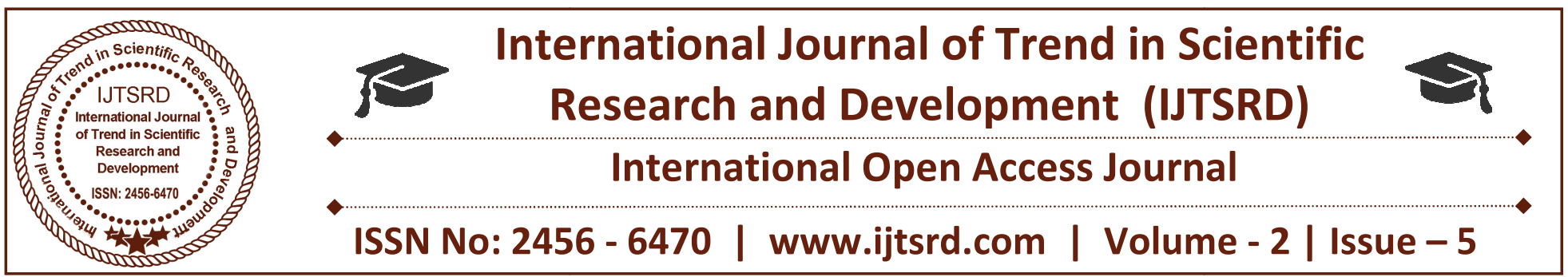

\title{
Public Economics
}

\author{
Muskan Dhakad \\ B.B.A., L.L.B (Hons), Indore Institute of Law \\ Indore, Madhya Pradesh, India
}

\section{ABSTRACT}

Public economics is based on the policies of the government. Public economics aspects (or financial aspects of people in general division) is the investigation of government arrangement through the viewpoint of monetary proficiency and value.

At its most fundamental level, public economics aspects gives a system to pondering regardless of whether the administration ought to take an interest in monetary markets and to what degree it ought to do as such. Keeping in mind the end goal to do this, microeconomic hypothesis is used to survey whether the private market is probably going to give proficient results without legislative impedance. Characteristically, this investigation includes the examination of government tax assessment and consumptions. This subject incorporates a large group of points including market disappointments, externalities, and the creation and execution of government approach. Public economics matters expands on the hypothesis of welfare financial matters and is eventually utilized as an apparatus to enhance social welfare. Wide techniques and points include the hypothesis and use of open finance examination and outline of open policy distributional impacts of tax assessment and government expenditures examination of market failure and government failure. Accentuation is on diagnostic and logical strategies and regularizing moral examination, as recognized from belief system. Cases of subjects secured are impose incidence, ideal taxation, and the hypothesis of open merchandise

Keywords: public sector ,private sector, economics, taxation.

\section{INTRODUCTION}

Public economics (or financial aspects of general society part) is the investigation of government arrangement through the viewpoint of monetary effectiveness and value.

At its most essential level, open financial aspects gives a system to contemplating regardless of whether the administration ought to take part in monetary markets and to what degree it ought to do as such. To do this, microeconomic hypothesis is used to survey whether the private market is probably going to give productive results without legislative impedance. Characteristically, this investigation includes the examination of government tax assessment and consumptions. This subject envelops a large group of themes including market disappointments, externalities, and the creation and execution of government approach. Public economics expands on the hypothesis of welfare financial aspects and is at last utilized as an instrument to enhance social welfare.

$>$ Expansive techniques and points include.

$>$ The hypothesis and utilization of open finance.

> Investigation and outline of open policy.

Distributional impacts of tax collection and government expenditures.

$>$ Investigation of market failure

$>$ Government failure.

\section{PUBLIC GOODS -}

It is unbelievable; we accept free goods and facilities every day we're just so familiar to them that we don't often notice. For example, when you decrease in a cool cafe on a hot summer day, you are receiving the advantage of air preparing that you are not compensating for. This is an example of a public good. Public goods are products or services we all 
use. Because we all use them, each of us cannot be charged independently for them. The café you appreciate couldn't really put a number on how much air preparing you enjoyed during your visit, so the owners cannot honestly charge you for it.

Public goods are classically financed by industrial holders or the government through tax incomes. When a public good is expended, the amount left for others to consume is not reduced, and it cannot be withdrawn from those who are unable to fee for it. For example, when you appreciate the air training in a café, there is not fewer air conditioning for others to enjoy. There is no struggle to offer public goods because they are provided to everyone. The police force is a good example of this. When we sense unsafe because we have got strange sounds late at night, we do not select which corporation to call. We simply call the police. Because there is no opposition among creators and workers for public goods, they are mentioned to as non-rivalrous and non-excludable. Non-excludable means that no one can be deprived of the provision. For example, anyone who impressions unsafe can call the police.

Theory of public goods - The theory of public goods was nominated by Paul Samuelson (1954). It states that goods that are communally consumed are nonrival and non-excludable. He also referred to the theory as The Pure Theory of Public Expenditure. The theory highpoints what Samuelson referred to as free riders--those who invented to have less than they do in order to contribute in the cooperative drinking without donating to its maintenance. An example of the free qualification aspect of the theory would be the entrepreneur who is charging $\$ 10$ for customers to watch the July 4th fireworks. Rather than pay, many free riders allow others to pay, while they enjoy the show from their windows or yards or from a nearby public area.

\section{TAXATION}

Private deliberate exchanges, starting with one individual then onto the next, might be subject to tax collection under a salary or utilization assess and additionally under a impose administration pointed specifically at exchanges. A run of the mill salary impose gives no conclusion for contributors' blessings, certainly regarding them as a type of utilization by givers, however prohibits blessing receipts from donees' duty base, which, as Simons (1938) contended, conflicts with the idea of completely burdening "salary." Under a money flow utilization impose, endowments could be considered utilization of givers, donees, or both; the last choice isn't customarily proposed yet by the by appears to be generally steady with the idea of burdening all "utilization," comprehended on account of givers as per uncovered inclination (by differentiation to comprehensive utilization of resources). Under a business assessment or VAT, blessings in essence are not secured, with the outcome that exclusive donees are exhausted, when they utilize endowments to finance their own, immediate utilization.

Freely, exchange tax assessment-collects on givers' blessings and inheritances in the United States and on legacies that donees get in numerous different nations-is regularly connected to wilful exchanges including genuinely large amounts of riches. Note that, albeit now and again considered together, the tax collection of riches exchanges under any appearance is subjectively particular from the tax collection of riches property, the last having been inspected in subsection 9.B.2 as a types of capital pay taxation Analytically, it is useful to overlook these distinctions among conceivable types of exchange tax collection and essentially to consider what net expense or sponsorship, assuming any, ought to be connected to intentional exchanges. For accommodation, the gauge (with respect to which a duty or endowment is estimated) utilized here is an unadulterated work pay charge administration, and any duty or endowment on exchanges is taken to be exacted on the donor. The examination starts by applying the system of section 6 on product tax collection. Possess utilization and blessings might be seen as two distinct items accessible to forthcoming benefactors (from this point forward, basically alluded to as givers). Specifically, as previously, it will be gathered that any pondered change in the treatment of exchanges is went with by a change of the work pay assess plan that holds givers' utilities consistent. Surrounded in this way, the inquiry is whether benefactors at any given salary level ought to be exhausted pretty much on account of giving an extra dollar to a donee as opposed to consuming it on claim utilization. On the off chance that blessings were subjectively like utilization of some other product, the benchmark result would be that no expense or appropriation is ideal. Notwithstanding taking note of the standard qualifi cations, more broad consideration will be given to unmistakable highlights of blessings. To start with, endowments customarily involve outside impacts with 
respect to donees, both specifically and furthermore in a roundabout way because of donees' work supply reactions. Second, blessings have suggestions with respect to benefactors' and donees' utility levels and peripheral utilities of consumption, which are pertinent to the marginal social value of redistribution.

\section{ANALYSIS OF MARKET FAILURE AND GOVERNMENT FAILURE}

On what basis is one to accomplish that a policy to accurate a market failure is as successful as imaginable. The first thought is whether government has any reason to interfere in a market. Is there evidence of a thoughtful market disaster to correct. The second is whether government procedure is at least improving market presentation. Is it reducing the commercial inefficiency, or "deadweight" loss, from market failure. Of course, the policy could be an "expensive" success by producing benefits that beat costs, but a cquiringun necessary cost to obtain the assistances. Hence, the final reflection is whether government policy is optimum it is efficientlymodifying the market disaster and exploiting economic welfare. Direction failure, then, ascends when government has formed inefficiencies because it should not have interfered in the first place or when it could have cracked a given problem or set of problems more professionally, that is, by producing greater net benefits. In other words, the theoretical standard of Pareto optimality could be used to assess government performance just as it is used to evaluate market performance. Of course, the ideal of a completely effectual market is hardly, if ever, observed in practice. From a policy perception, market failure should be a matter of concern when market performance expressively deviates from the suitable efficiency benchmark. Similarly, a government failure should call a government involvement into question when economic welfare is actually concentrated or when resources are apportioned in a manner that expressively deviates from an appropriate efficiency benchmark. The disappointing outcome of government's current microeconomic policies should be of great concern to everyone interested in public affairs regardless of political encouragement or occupation. By supporting government's presentation and indicating how it can be better, I hope to do more than set a "limit to infinite error."

\section{COST BENEFIT ANALYSIS}

It can be explained as a procedure for estimating all costs involved and possible profits to be derived from a business opportunity or proposal. It takes into account both quantitative and qualitative factors for analysis of the value for money for a particular project or investment opportunity. Benefits to costs ratio and other indicators are used to conduct such analyses. The objective is to ascertain the soundness of any investment opportunity and provide a basis for making comparisons with other such proposals. All positives and negatives of the project are first quantified in monetary terms and then adjusted for their time-value to obtain correct estimates for conduct of cost-benefit analysis. Most economists also account for opportunity costs of the investment in the project to get the costs involved. The comparison of costs and benefits of public goods projects to decide if they should be undertaken. ${ }^{1}$

5.1 Measuring current costs - Cash-flow accounting: Accounting method that calculates costs solely by adding up what the government pays for inputs to a project, and calculates benefits solely by adding up income or government revenues generated by the project. Opportunity cost: The social marginal cost of any resource is the value of that resource in its next best use.

5.2 Opportunity cost - The social marginal cost of any resource is the value of that resource in its next best use.

5.3 General rule: Economic costs are only those costs associated with diverting the resource from its next best use Perfectly Competitive Markets Social Cost $=$ Price (true for labor and material) Imperfectly Competitive Markets

A. Monopoly: (suppose asphalt is produced by monopoly)Price $=$ Marginal cost + Monopoly Marginal Profit > Marginal costOn efficiency grounds, Social cost $=$ Marginal costProfit is a transfer from govt (taxpayers) to monopoly (this matters for redistribution but not efficiency)

B. Labor market with unemployment: Suppose a minimum wage setat $\$ 10$ creates involuntary unemploymentThe unemployed would be willing to work for $\$ 6$ on average but cannotfind jobs.

${ }^{1}$ https://economictimes.indiatimes.com/definition/cost-pushinflation 


\section{ISSUES IN COST-BENEFIT ANALYSIS}

Common Counting Mistakes: When analyzing costs and benefits, a number of common mistakes arise, such as:-

$>$ Counting secondary benefits (e.g., more commerce activity around new highway comes at the expense of other places)

$>$ Counting labor as a benefit (e.g., labor is a cost, jobs created means those workers do not produce something else)

$>$ Double-counting benefits (eg rise in house values due to reduced commuting cost)

Distributional Concerns: The costs and benefits of a public project do not necessarily accrue to the same individuals.

Uncertainty: The costs and benefits of public projects are often highly uncertain. ${ }^{2}$

\section{PUBLIC AND PRIVATE SECTOR}

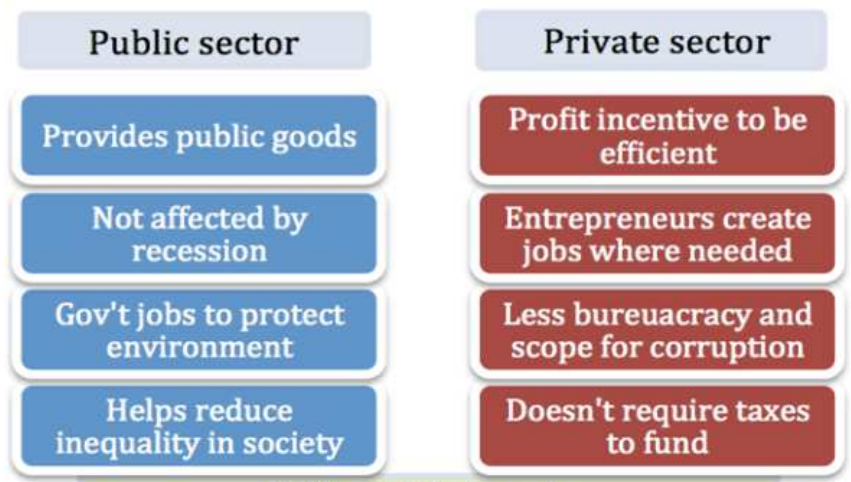

Public vs Private sector

\section{A. private sector}

Profit Incentive. Private firms have a profit incentive to cut costs and develop products demanded by consumers. In the government sector, this profit motive is often absent. Therefore government bodies have a greater tendency to be overstaffed and inefficient Bureaucracy. For political reasons, it is sometimes more difficult to get rid of surplus workers in the public sector than the private sector. Private businessmen don't have to worry about political popularity and so are more willing to make people redundant if it helps efficiency. The public sector, on the other hand, is more likely to employ surplus workers in unproductive jobs. Crowding out. If the public sector increases, then this is reducing resources for the private sector. For

${ }^{2}$ https://eml.berkeley.edu/ saez/course131/costbenefit_ch08.pdf example, if we raise taxes to increase government spending then this means the private sector has lower resources for private sector investment. Therefore, if government spending can be reduced it will free up resources for more efficient private sector growth and job creation. Though there may be temporary problems from public sector spending cuts, in the long term, it will enable lower taxes and higher private sector investment. Government spending that discourages productivity.

\section{B. Public sector}

Public Goods -The private sector is very unlikely to provide public goods because of the free rider problem. Therefore, the government needs to provide nearly all goods with the characteristics of public goods. This includes street cleaning, military, police and the judicial system.

Merit goods and positive externalities- Goods with positive externalities will be under-consumed in a free market. For example, education and training could be provided in the free market, but generally there is under-consumption of the socially optimal level because private firms ignore positive externalities. Therefore, the government needs to intervene in public services such as health and education. By providing good quality training schemes, the government can help increase labour productivity and provide private firms with educated workers. The same argument applies to investment in infrastructure. E.g. New train links, and roads. ${ }^{3}$

\section{CONCLUSION}

Public economics include the economics of public spending, of taxation to pay for that spending, and of policy and programs broadly-defined. Faculty and students of public economics at CSU are engaged in active research in a wide array of opportune public policy topics connected to health, immigration, education, tax policy, and the welfare state, and often deliver advice to policymakers at several levels of government. Courses and inquiry often share commonalities and complementarities with other practical fields such as regional economics, environmental economics and economic development, and therefore the field is a natural one to association with other major areas of study at CSU. Classes review classic and recent literature and aim near expanding analytics to original investigation that is applicable to economic strategy.

${ }^{3}$ http://www.shareyouressays.com/essays/essay-on-privatesector-vs-public-sector/88039 